\title{
Impaired quality of life after pneumonectomy: Who is at risk?
}

\author{
Francesco Leo, MD, PhD, ${ }^{\text {a }}$ Paolo Scanagatta, $\mathrm{MD},{ }^{\mathrm{a}}$ Fernando Vannucci, MD, ${ }^{\mathrm{a}}$ Daniela Brambilla, MA, \\ Davide Radice, $\mathrm{PhD},{ }^{\mathrm{b}}$ and Lorenzo Spaggiari, $\mathrm{MD}, \mathrm{PhD}^{\mathrm{a}, \mathrm{c}}$
}

Objective: After pneumonectomy, quality of life may be impaired in a proportion of patients because of the presence of symptoms causing severe limitations in daily activities. This is a prospective study on patients who have undergone pneumonectomy for cancer, assessing quality of life modifications 6 months after surgery.

\begin{abstract}
Methods: Beginning in August 2006, candidates for pneumonectomy had their quality of life assessed by the European Organization for Research and Treatment of Cancer questionnaire (QLQ-C30+LC13) preoperatively and at 1,3 , and 6 months after surgery. Poor quality of life at 6 months was defined as global health values $10 \%$ or more below baseline values. The impact of several clinical variables was tested to discover predictors of poor postoperative quality of life.
\end{abstract}

Results: Forty-one of the 50 patients enrolled in the study had a complete quality of life follow-up by January 2008 , representing the population of the study. Six months after pneumonectomy, global health showed a minimal impairment in the whole population (baseline $60.4 \pm 26.5$, at 6 months $56.3 \pm 24.2, P=.15$ ). Ten patients $(24.4 \%)$ were identified as having poor quality of life at 6 months. Age of 70 years or more was identified as a significant risk factor for poor 6-month quality of life using multivariate analysis (odds ratio, 1.13 ; $95 \%$ confidence interval, 1-1.26). The baseline global health score was the strongest predictor of postoperative global health quality of life (odds ratio, $0.16 ; 95 \%$ confidence interval, $0.02-0.46 ; P=.0086$ ).

Conclusion: The overall quality of life after pneumonectomy was impaired in $25 \%$ of surviving patients at 6 months after surgery; thus, this aspect of recovery should be routinely discussed with patients before pneumonectomy. Patients aged 70 years or more and those with low preoperative quality of life seem to be at risk for unsatisfactory quality of life after surgery. (J Thorac Cardiovasc Surg 2010;139:49-52)

Quality of life (QoL) is an important issue in oncology, ${ }^{1,2}$ not only defining the absence of disease but also measuring physical, mental, and social well-being. ${ }^{3}$ Lung cancer surgery may affect QoL, ${ }^{4,5}$ particularly when pneumonectomy is required to obtain a radical resection. ${ }^{6}$ Apart from early postoperative mortality, ${ }^{7-10}$ pneumonectomy has been reported as being extremely detrimental in terms of QoL because of a greater incidence of dyspnea and a decrease in physical functions, compared with patients undergoing less dramatic resections. ${ }^{5}$ The impact of this impairment remains controversial, and little information is present in the literature. This study was designed to prospectively monitor QoL after pneumonectomy, with the aim of defining the potential risk factors of poor postoperative QoL.

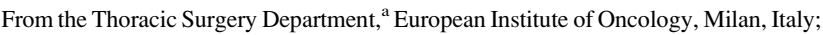
Epidemiology and Biostatistics, ${ }^{\mathrm{b}}$ European Institute of Oncology, Milan, Italy; and School of Medicine, ${ }^{\mathrm{c}}$ University of Milan, Italy.

Preliminary results from this study were presented as a poster during the 16th Conference on General Thoracic Surgery held in Bologna in June 2008.

Received for publication Sept 5, 2008; revisions received May 4, 2009; accepted for publication May 31, 2009; available ahead of print July 30, 2009.

Address for reprints: Francesco Leo, MD, PhD, Thoracic Surgery Department, National Cancer Institute, Via Venezian 1, 20100 Milan, Italy (E-mail: francesco. leo@istitutotumori.mi.it).

0022-5223/\$36.00

Copyright (c) 2010 by The American Association for Thoracic Surgery doi:10.1016/j.jtcvs.2009.05.029
}

\section{MATERIALS AND METHODS}

A prospective observational study was designed to assess QoL modifications during the first 6 months after surgery in a series of 50 consecutive patients undergoing pneumonectomy for lung cancer at the Thoracic Surgery Department of the European Institute of Oncology. During the considered period, a postoperative predicted forced expiratory volume in 1 second less than $30 \%$ was considered a contraindication to pneumonectomy.

All patients for whom a pneumonectomy was planned were considered eligible for the study, thereafter excluding those patients who underwent lesser resections. QoL was assessed at admission and 6 months after surgery by the administration of the Italian version of the European Organization for Research and Treatment of Cancer questionnaire QLQ-C30 and the specific lung module LC13. Raw scores were then standardized by linear transformation (range, 0-100). This questionnaire, widely used in thoracic oncology, was chosen because of its focus on psycho-social aspects and typical symptoms of patients treated by multimodality protocols, commonly used in our practice.

The QLQ-C30 assessment focused on global QoL (global health [GH]), functional domains (physical, role, emotional, cognitive, and social) and 8 symptoms (fatigue, nausea and vomiting, pain, dyspnea, insomnia, appetite loss, constipation, and diarrhea). High scores for the functional and overall QoL scales indicate a higher/healthier level. High scores for the symptom scales represent a higher level of symptoms/problems. Missing data were managed following European Organization for Research and Treatment of Cancer Quality of Life Group guidelines: ${ }^{2,11}$ If at least half of the items from the scale were answered, it was assumed that the missing items had values equal to the average of those items that were present for that respondent. Otherwise, the score was set to missing.

Comparison of QoL scores at baseline and at 6 months was performed by the use of a $t$ test for paired values. Impaired QoL at 6 months was defined as a decrease in the GH status score of at least $10 \%$ from the baseline, because lower differences are usually perceived by patients as minimal. ${ }^{12}$ Impaired 


\section{Abbreviation and Acronym \\ $\mathrm{QoL}=$ quality of life}

QoL at 6 months was considered as an outcome variable in a logistic regression model, using 10 covariates (age, sex, smoking status, American Society of Anesthesiologists score, postoperative predicted forced expiratory volume in 1 second, neoadjuvant treatment, side of pneumonectomy, type of pneumonectomy, postoperative complications, and adjuvant treatment). The risk ratio and corresponding $95 \%$ confidence intervals were reported for covariates considered clinically relevant or statistically significant at the .05 significance level (Wald chi-square test) and then included in the final multivariate model.

\section{RESULTS}

During a period of 13 months, 240 lung cancer resections were performed, including 56 patients considered eligible for pneumonectomy, 6 of whom underwent bronchoplasty procedures and were thus excluded from the study. Three patients died postoperatively, and 2 additional patients died within 3 months of surgery. Items expressing GH status remained missing for 4 patients and were excluded from the analysis. The final study population comprised 41 patients. Their clinical characteristics are expressed in Table 1.

Six months after pneumonectomy, GH showed no significant impairment in terms of the population as a whole (baseline $60.4 \pm 26.5$, at 6 months $56.3 \pm 24.2, P=.15$, Figure 1). An increased negative effect was recorded in the social functioning item $(81.7 \pm 29.7$ vs $71.9 \pm 31$, $P=.002$, Table 2 ), the dyspnea score, the pain score, and the nausea and vomiting score. Most patients also reported increased financial difficulties after surgery $(P=.005)$. On the other hand, patients' emotional functioning (76.3 \pm 18.3 vs $88 \pm 18.2, P<.0001)$ and cognitive functioning $(87.8 \pm 19$ vs $95.1 \pm 13.6, P=.008)$ were reported as improved.

Ten patients $(24.4 \%)$ were defined as having impaired QoL at 6 months. Of the 4 factors identified at univariate analysis (age, induction treatment, postoperative complications, and adjuvant treatment), only the factor of age 70 years or more was identified as a risk factor for the occurrence of 6-month impaired QoL (odds ratio 1.13; 95\% confidence interval, 1.1-2.6).

Analysis of the correlation between preoperative and 6month GH scores revealed a linear relationship for patients with low QoL at baseline. The baseline GH score was the strongest predictor of postoperative QoL (odds ratio, 0.16; $95 \%$ confidence interval, $0.02-0.46 ; P=.0086$ ). The corresponding receiver operating characteristic curve expresses a notably high area under the curve estimate (0.92).

\section{DISCUSSION}

QoL should be routinely assessed when major surgery is required in cancer treatment. This is particularly true in the
TABLE 1. Patient characteristics in the study population

\begin{tabular}{lcccc}
\hline \multicolumn{1}{c}{ Demographics } & N & Mean \pm SD & Median & Min-Max \\
\hline Age (y) & 41 & $60 \pm 9$ & 61 & $36-77$ \\
Respiratory functions & & & & \\
$\quad$ FEV $_{1}$ (\%) & 40 & $83.1 \pm 15.9$ & 84.1 & $53-136$ \\
$\quad$ DLco/Va (\%) & 40 & $91.2 \pm 16.4$ & 89.7 & $59-126$ \\
$\quad$ Perfusion (\%) of the & 39 & $35.2 \pm 10.1$ & 35.0 & $6-56$ \\
$\quad$ removed lung & & & & \\
& Counts & & $(\%)$ & \\
Gender & Female & 9 & $22.0 \%$ & \\
& Male & 32 & $78.0 \%$ & \\
Neoadjuvant treatment & 21 & & $53.8 \%$ & \\
Surgical details & & & & \\
$\quad$ Right pneumonectomy & 14 & & $34.1 \%$ & \\
$\quad$ Left pneumonectomy & 27 & & $65.8 \%$ & \\
$\quad$ Extended procedure & 8 & & $19.5 \%$ & \\
Postoperative complications & & & & \\
$\quad$ Reoperation & 6 & & $14.6 \%$ & \\
$\quad$ ARDS & 1 & & $2.4 \%$ & \\
$\quad$ Bronchial fistula & 1 & & $2.4 \%$ & \\
\hline
\end{tabular}

$S D$, Standard deviation; $A R D S$, acute respiratory distress syndrome; $F E V_{l}$, forced expiratory volume in 1 second; $D L C O / V a$, diffusion capacity for carbon monoxide adjusted for alveolar volume.

case of pneumonectomy, which is often performed after neoadjuvant treatment (in cases of T4 tumors or minimal N2 disease responding to chemotherapy at the European Institute of Oncology) or before adjuvant therapy, when the detrimental effects of a treatment on QoL have a cumulative effect on subsequent treatments.

This series reported only minimal overall QoL impairment after pneumonectomy, probably because of the balance between the worsening of symptoms and the improvement of psychologic well-being, due to the positive expectation of having their cancer definitively cured by surgical intervention.

Nevertheless, 1 of 4 patients registered a significant QoL decrease. The cause of that decrease may be represented

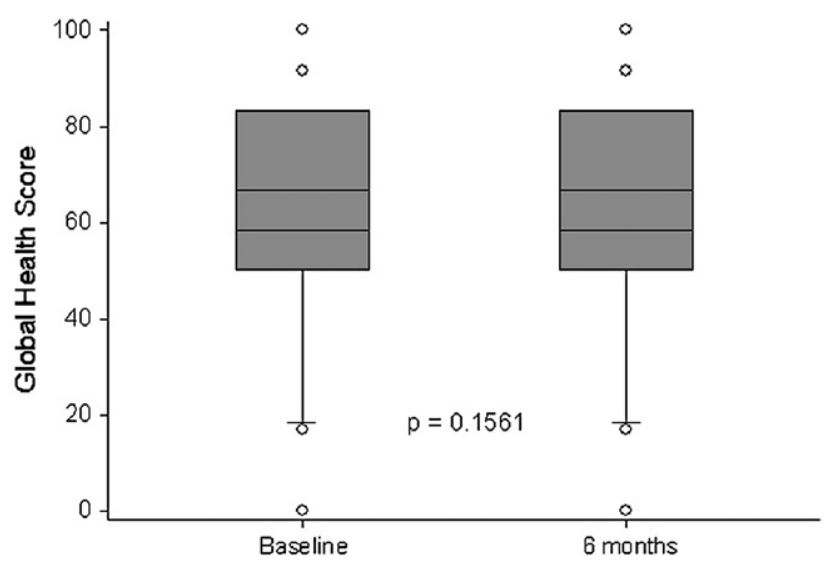

FIGURE 1. Six months after pneumonectomy, GH showed a minimal impairment in the whole population (baseline $60.4 \pm 26.5$, at 6 months $56.3 \pm$ $24.2, P=.15)$. 
TABLE 2. Comparison of preoperative and postoperative scores from the European Organization for Research and Treatment of Cancer QLQ-C30 and LC-13 questionnaires

\begin{tabular}{|c|c|c|c|c|c|}
\hline \multirow{2}{*}{$\frac{\text { Questionnaire }}{\text { EORTC QLQ-C30 }}$} & \multicolumn{2}{|c|}{ Before pneumonectomy } & \multicolumn{2}{|c|}{ Six months after pneumonectomy } & \multirow[t]{2}{*}{$P$ value } \\
\hline & Mean & SD & Mean & SD & \\
\hline \multicolumn{6}{|l|}{ GH status/QoL } \\
\hline GH status QL2 & 60.4 & 26.5 & 56.3 & 24.2 & .15 \\
\hline \multicolumn{6}{|l|}{ Functional scales } \\
\hline Physical functioning PF2 & 76.3 & 25.9 & 71.1 & 25.6 & .82 \\
\hline Role functioning RF2 & 77.8 & 30.7 & 74.4 & 32.9 & .09 \\
\hline Emotional functioning EF & 76.3 & 18.3 & 88 & 18.2 & $<.001$ \\
\hline Cognitive functioning $\mathrm{CF}$ & 87.8 & 19 & 95.1 & 13.6 & .008 \\
\hline Social functioning SF & 81.7 & 29.7 & 71.9 & 31 & .002 \\
\hline \multicolumn{6}{|l|}{ Symptom scales/items } \\
\hline Fatigue FA & 25.3 & 24.8 & 29.5 & 24.7 & .08 \\
\hline Nausea and vomiting NV & 4.5 & 11.2 & 11 & 16.9 & .02 \\
\hline Pain PA & 18.7 & 31.4 & 29.7 & 31.5 & $<.001$ \\
\hline Dyspnea DY & 26 & 29.3 & 35.8 & 28.3 & .38 \\
\hline Insomnia SL & 18.3 & 30.1 & 14.6 & 26.9 & .43 \\
\hline Appetite loss AP & 13 & 20.9 & 18.7 & 23.6 & .15 \\
\hline Constipation $\mathrm{CO}$ & 17.1 & 22.5 & 11.4 & 19.2 & .11 \\
\hline Diarrhea DI & 4.9 & 14.1 & 4.1 & 11 & .11 \\
\hline Financial difficulties FI & 12.5 & 22.2 & 5.8 & 16.7 & .005 \\
\hline \multicolumn{6}{|l|}{ EORTC LC13 } \\
\hline \multicolumn{6}{|l|}{ Symptom scales/items } \\
\hline Dyspnea LCDY & 20.2 & 20.6 & 32.5 & 20.2 & $<.001$ \\
\hline Coughing LCCO & 30 & 22.4 & 28.4 & 20.5 & .80 \\
\hline Sore mouth LCSM & 3.3 & 10.1 & 4.2 & 13.5 & 1 \\
\hline Dysphagia LCDS & 5.8 & 16.7 & 10 & 18.8 & .12 \\
\hline Peripheral neuropathy LCPN & 7.5 & 14.1 & 5 & 14.2 & .54 \\
\hline Alopecia LCHR & 6.7 & 17.2 & 12.2 & 28.6 & .24 \\
\hline Pain in chest LCPC & 6.7 & 15.5 & 8.5 & 19.8 & .56 \\
\hline Pain in arm or shoulder LCPA & 7.5 & 20.6 & 15 & 26.1 & .09 \\
\hline Pain in other parts LCPO & 21.6 & 34.7 & 23.9 & 31.5 & .84 \\
\hline
\end{tabular}

EORTC, European Organization for Research and Treatment of Cancer; $G H$, global health; $Q o L$, quality of life.

by cardiopulmonary response to surgery, because that figure is extremely close to the percentage of patients who failed to increase their cardiac index after pneumonectomy $(20 \%){ }^{13}$ It is reasonable to assume that impaired cardiac response may translate into impaired QoL; thus, treating the first would consequently improve the second. Unfortunately, this interpretation remains speculative, as to date, no existing evidence confirms this hypothesis.

As previously reported, ${ }^{14}$ no clinical parameter apart from age was identified as a risk factor for QoL impairment 6 months after pneumonectomy. Analysis of score distribution suggested that, in patients with low preoperative QoL, postoperative QoL was not affected by pneumonectomy. Patients with high QoL levels at baseline however, were more likely to exhibit QoL impairments of unpredictable nature.

An additional QoL issue is how to consider patients who died within 6 months of pneumonectomy. These patients were not included in our analysis and were registered as having a QoL score of 0 because QoL cannot be expressed without patients' judgment. Nevertheless, these deaths are usually the final event in a rapid and progressive decline in QoL, which usually remains unreported, constituting an additional risk of which patients should be informed.

\section{CONCLUSIONS}

The overall QoL after pneumonectomy was impaired in $25 \%$ of cases, an aspect that should be routinely discussed with patients before surgery. Patients aged 70 years or more and those with low preoperative QoL seem to be at highest risk for reduced QoL after surgery.

The authors thank Kendall Katze for reviewing the English version of the article.

\section{References}

1. Aaronson NK, Ahmedzai S, Bergman B, Bullinger M, Cull A, Duez NJ, et al. The European Organization for Research and Treatment of Cancer QLQ-C30: a quality-of-life instrument for use in international clinical trials in oncology. J Natl Cancer Inst. 1993;85:365-76.

2. Earle CC. Outcomes research in lung cancer. J Natl Cancer Inst. 2004;33:56-77.

3. World Health Organization. Constitution of the World Health Organization: Chronicle of the World Health Organization 1. Geneva, Switzerland: World Health Organization; 1947. 
4. Handy JR, Asaph JW, Skokan L, Reed CE, Koh S, Brooks G, et al. What happens to patients undergoing lung cancer surgery? Outcomes and quality of life before and after surgery. Chest. 2002;122:21-30.

5. Zieren HU, Muller JM, Hamberger U, Pichlmaier H. Quality of life after surgical therapy of bronchogenic carcinoma. Eur J Cardiothor Surg. 1996;10: 233-7.

6. Patterson GA. Extended pulmonary resection: In: Pearson FG, Cooper JD, Deslauriers J, Lerut AEM, Luketich JD, Rice TW, et al, eds. Thoracic surgery. Volume 1, 2nd ed. New York: Churchill-Livingstone; 2002:1045-61.

7. Boffa DJ, Allen MS, Grab JD, Gaissert HA, Harpole DH, Wright CD. Data from the Society of Thoracic Surgeons General Thoracic Surgery database: the surgical management of primary lung tumors. J Thorac Cardiovasc Surg. 2008;135: 247-54.

8. Ginsberg RJ, Hil LD, Eagan RT. Modern thirty day mortality of surgical resections in lung cancer. J Thorac Cardiovasc Surg. 1983;86:654-8.

9. Doddoli C, Barlesi F, Trousse D, Robitail S, Yena S, Astoul P, et al. One hundred consecutive pneumonectomies after induction therapy for non-small cell lung cancer: an uncertain balance between risks and benefits. $J$ Thorac Cardiovasc Surg. 2005;130:416-25.

10. Leo F, Solli P, Veronesi G, Radice D, Floridi A, Gasparri R, et al. Does chemotherapy increase the risk of respiratory complications after pneumonectomy? J Thorac Cardiovasc Surg. 2006;132:519-23.

11. Fayers P, Aaronson NK, Bjordal K, Curran D, Groenvold M on behalf of the EORTC Quality of Life Study Group. EORTC QLQ-C30 scoring manual: 2nd Edition. Brussels: Quality of Life Unit. EORTC Data Centre; 1999.

12. Osoba D, Aaronson NK, Zee B, Sprangers MAG, te Velde A. Modification of the EORTC QLQC30 (version 2.0) based upon content validity and reliability testing in large samples of patients with cancer. Qual Life Res. 1997;6:103-8.

13. Leo F, Tullii M, Della Grazia L, Attanasio A, Tosoni A, Manfredi G, et al. What happens after pneumonectomy? A prospective study using the transpulmonary thermodilution method. J Thorac Cardiovasc Surg. 2008;135:210-1.

14. Brunelli A, Socci L, Refai M, Salati M, Xiumè F, Sabbatici A. Quality of life before and after major lung resection for lung cancer: a prospective follow-up analysis. Ann Thorac Surg. 2007;84:410-6. 